\title{
Engineering Education Study: Software Engineering Teaching Valuation In Colleges Of China
}

\author{
Weizhu Zhong \\ Management school,TJUT \\ Tianjin, China
}

\author{
Chenxuan Song \\ Management school,TJUT \\ Tianjin, China
}

\author{
Lingling Xi \\ Management school,TJUT \\ Tianjin, China
}

\begin{abstract}
In the basis of empirical research, the viewpoint that is about the old theory of teaching contents and weak experiment teaching in China's universities is proposed. This leads to the phenomenon that the standard of information graduates is not suited to the development of software industry. The data of teaching satisfaction about the software engineering comes from questionnaires of $\mathbf{1 0 0}$ software professionals who have graduated from colleges for 3 5 years in Tianjin. The conclusion that software testing and experimental teaching should be strengthened in the proportion of teaching curriculum is got through the principal components analysis and quaternary graph. It points out a direction for the development of "Software engineering" curriculum.
\end{abstract}

Key words-software engineering; education reform; empirical research

\section{INTRODUCTION}

'Software engineering' presented for the first time was in 1968, software engineering concepts, frameworks, methods and means formed in the 70 's, 80 's, technology of object-oriented methods has received extensive attention, after the 90 's, the important development of software engineer in was based on component $[1,2,3,4]$. With the development of software technology, its importance is more apparent, many colleges and universities offer software engineering courses. Recommended computer science curriculum and the state recommended curriculum according to the international ACM/IEEE-CS, it is one of the nine main courses of computer science [5,6,7]. Roughly speaking, the software engineering is an independent cross engineering disciplines, computer science, engineering and management principles are applied to software development and maintenance through this course, especially on the analysis and evaluation of large-scale software, specifications, design and evolution $[8,9,10]$. This course focus on developing the ability of solving global problems for students and its teaching mission is to cultivate information engineering talents of the new century.

At present, on one hand the software and related professional graduates of colleges and universities are facing a career predicament; On the other hand the business development of a large number of software companies are struggling with recruiting the right professionals in order to face the talent shortage. This situation stems from software talents training structures and the quality problems, the fundamental reason is that the course of teaching content and teaching methods is incompatible with enterprise development, the theory is divorced from reality and weak link in the practice, the academics divorced from the practice is more serious $[11,12,13]$. To solve the above problems, many scholars carried out relevant researches about software engineering in teaching methods and practice. $\mathrm{Li}$ Guanyuan, Ma Nan(2011)studied abroad course on software engineering characteristics and proposed using different teaching methods according to the characteristics of the different phases of software life-cycle[14].Wang Canhui, Lin Langdie(2010) proposed that the software engineering ideas should run thought the computer teaching, arguing that teachers should not only teach basic knowledge of programming languages, but also should teach students how to write programs and developing software[15].In the practical study, Wang Hui (2007) used engineering method in teaching management system in colleges and universities, and discussed how to apply object-oriented software engineering thought to CEMIS systems application development[16].Besides, Wu Guodong(2010) made an integrated "project driven, a paradigm case ,reproduction ,team practice" teaching model of integration; Guo Jun, Zhang Hong xia, ect(2010) depicted the teaching system of multiple perspectives based on the angle of view of perspectives, methods and tools[17,18]. In a word, the development of software engineering not only focuses on the theoretical knowledge but also on the empirical ability. In the basis of empirical study, the viewpoint that the standard of information graduates is not suited to the development of software industry and the construction of curriculum system are proposed. 


\section{REVIEW}

\section{A. Teaching Mode}

At present, the teaching model of software engineering is heavy theory and light practice which is mainly based on teachers 'classroom teaching and students are just passively accept knowledge. This teaching method is difficult to arouse students' interest, as well as active and creative[19]. The usage of teaching materials is as follows: "Introduction to the software engineering" edited by Zhang haifan account for 50percent; "Practical software engineering" edited by Zheng renjie account for 20percent; the teaching materials edited by other editors account for 10percent.The units of the University is as follows: 54 hours accounted for 40percent; 32 hours accounted for 30percent; 62 hours, 48 hours and 24 hours of each 10 percent. Generally speaking, theoretical lessons and practical lessons are distributed unequally, theoretical parts are on high side that account for more than 60percent. In summary, they are shown in table 1.

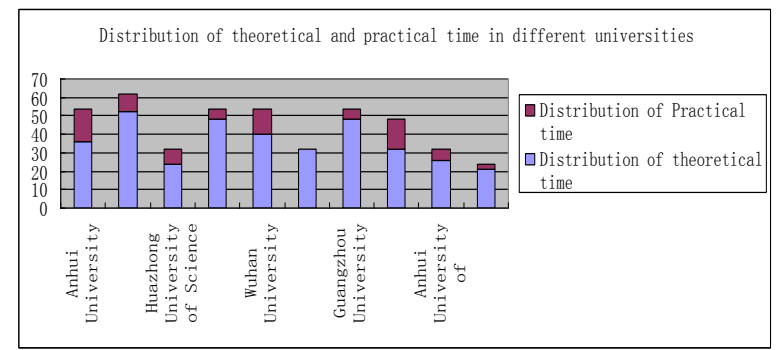

Figure 1. Theoretical and practical time

In Fig. 1, in half of the schools, the hours of practical course are more than 20percent: Anhui University and Hebei University of Technology, 33.3 percent; Wuhan University, 25.5 percent; Huazhong University of Science and Technology, 25percent; Nankai University, 20 percent. Overall, the practical teaching courses in half of universities are 1/5. Most of the software engineering course of the ten colleges and universities was opened in the School of Information or Computer Science.

Nowadays, there are many colleges having their own independent school of software in China, for example, Tsinghua University, Beijing University of Aeronautics \& Astronautics, Shanghai Jiaotong University and Sichuan University. Generally, software engineering undergraduate courses can be divided into general education courses, practical teaching of basic courses, professional courses and course [20]. The education courses of the four schools are accounted for one fifth through the research. The practical teaching in four universities is accounted for a certain amount, the average ratio reached $1 / 5$ in Tsinghua University, Sichuan University and Beijing University of aeronautics and the proportion of Shanghai Jiaotong University is less.

In all, the software engineering curriculum is offered by the school of information or independent software school, major colleges and universities are relatively weak in practical instruction, each IT-related company pay more attention to students' practical ability.

\section{B. The contents}

Above the ten universities, the textbook of "introduction to software engineering" edited by Zhang haifan is used in theoretical instruction of 50 percent universities. The teaching contents of this textbook are roughly as follows: the first chapter is about software crisis and software engineering, the second chapter is the feasibility study, the third chapter is needs analysis, chapter four : the overall design, chapter $\mathrm{V}$ : the detailed design and so on. Through the survey of lesson time allocation survey, we discovered that the third, fourth and fifth chapters account for the maximum numbers; the details are shown in Fig 2.

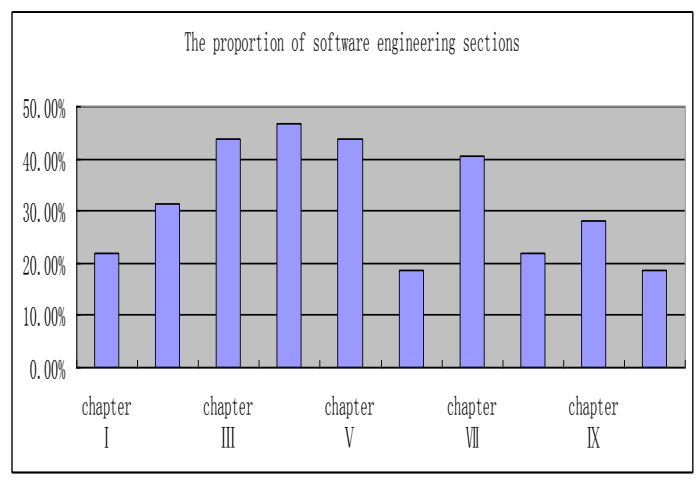

Figure 2. the proportion of software engineering

At present, the domestic of this course teaching focus on analysis, design and implementation for the traditional, however, the object-oriented research is still in the initial design stage. Object-oriented methods is a new way of thinking, it regard the program as a mutual agreement by independent of each collection. Each object is a tiny program, has its own data, operation, functionality, and purpose. In this way can make a big step in the direction of reducing the semantics faults. In many systems, the solution space objects can simulate the problem space objects, the solution space and the problem space structure is very consistent at the same time, so this program is easy to understand and maintain.

By investigating 14 well-known universities of the U.S. east and west, we found that the curriculum of object-oriented development, software analysis, software testing and maintenance accounted for most. The results are shown in figure 3. 


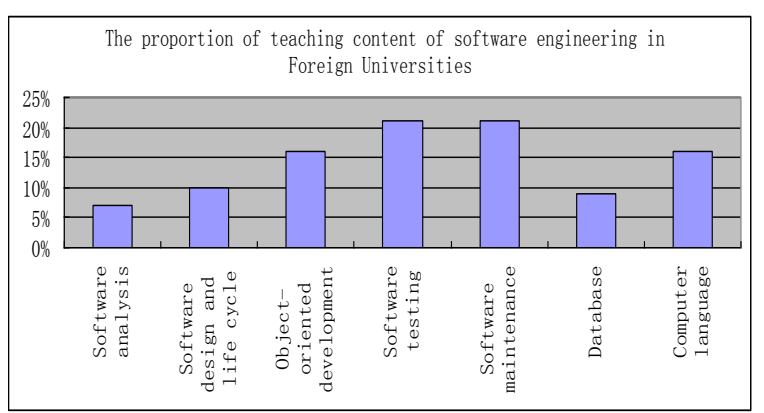

Figure 3. The proportion of teaching content in foreign universities

It can be learned from table 1 and table 2 that foreign universities and local universities are different in the teaching of software engineering. In analysis of theoretical instruction, the traditional demand, analysis and design are emphasized in domestic colleges, but the foreign universities are more stress to the software testing, maintenance, object-oriented development and computer language. In this paper, we take University of California, Berkeley [21] and Huazhong University as an example to confirm the similarities and differences between instructions in the course.

\section{1) The contents of theoretical instruction}

The "software engineering" curriculum offered by Huazhong University of Science and Technology includes the feasibility studies, software crisis and software engineering, etc. The contents about concept design, development and maintenance of large software systems and technologies; oriented functional and object-oriented modular design techniques for reusability and maintainability are included in the software engineering of the University of California, Berkeley. The content of software engineering course in Stanford University and Carnegie Mellon University is divided into multi-course, it is necessary because students can choose courses based on professional needs in this way, and each course can focus on in-depth instruction. Our teaching methods are similar to Berkeley.

\section{2) Class assignments and experimental operation}

The last comprehensive task of software engineering course offered by the Huazhong University of Science and Technology is very important, and the closed book form is used in the exam, the experimental teaching is a quarter of total teaching hours, and the evaluation of the examination of experimental course is based on a report. The form of project team to design and implement software projects in Berkeley is in order to enable students to obtain the actual operating experience. The completion of the experiment in National Universities is done independent, scoring method and standard of the course is similar to the Berkeley, but it can also reference a further breakdown of the school to motivate students to complete each phase carefully in the task of the software development. In short, the teaching mode pays more attention on theory than practice.

\section{Methodology}

Based on the phenomenon of old theoretical teaching and weak practical aspects, we designed the questionnaires that include five second-dimensions: the first part is used to fill the person's name, graduation year, industry and jobs belong in these areas. The second part is about the investigation of requirements on the skills of software engineering. The third part is the satisfaction survey of the teaching content of the software engineering; the fourth part is the satisfaction survey about practical instruction. The last part is about the recommendations and suggestions for the instruction reform.

The data of teaching satisfaction about the software engineering came from questionnaires of 100 software professionals who have graduated from colleges for $3 \sim 5$ years in Tianjin. We sent 100 electrical questionnaires and got back 90 , the total effective questionnaire was 85 . This process was from December 10, 2010 to September 16, 2011.

\section{RESULTS}

\section{A. Equations}

In this paper, the satisfaction survey on the theoretical contents and practical instruction of "software engineering" is proposed(the third and forth part of questionnaire) In the basis of fifth principle of the Likert Scale, "very satisfied, satisfied, satisfied, dissatisfied, and very dissatisfied with respectively" are assigned by $5,4,3,2,1$. Finally, we calculate the scores of students' satisfaction for each indicator according to the satisfaction formula.

Satisfaction scores in the quarter of the graph model is calculated as follows:

$$
\mathrm{P}_{\mathrm{i}}=\sum_{j=1}^{k} X_{j} Y_{i j} \quad(\mathrm{i}=1,2, \ldots \mathrm{n}, \mathrm{j}=1,2,3, \ldots \mathrm{k})
$$

$\mathrm{P}_{\mathrm{i}}$ : satisfaction with the graduates for I-index;

i number of the indicators that affect the satisfaction of graduates;

$X_{j}$ : satisfaction scores corresponding to the $\mathrm{j}$-level;

$\mathrm{J}$ : classification of satisfaction series;

$Y_{i j}$ : the proportion of the graduates when $\mathrm{i}$ index is at the level of $j$.

The results are shown in the following table 1.

The dimensional design of software engineering is also shown in table 2 . 
TABLE I. SATISFIED RESULTS OF THE SOFTWARE ENGINEERING COURSES

\begin{tabular}{|c|c|c|c|c|c|c|c|c|c|c|c|}
\hline & \multicolumn{2}{|c|}{ very satisfied } & \multicolumn{2}{l|}{ Satisfaction } & \multicolumn{2}{c|}{ Basic satisfaction } & \multicolumn{2}{l|}{ Not satisfied } & \multicolumn{2}{c|}{ Very dissatisfied } & Satisfaction average \\
\hline A01 & 0 & $0 \%$ & 6 & $7 \%$ & 27 & $32 \%$ & 41 & $48 \%$ & 11 & $13 \%$ & 2.33 \\
\hline A02 & 0 & $0 \%$ & 0 & $0 \%$ & 12 & $14 \%$ & 49 & $58 \%$ & 24 & $28 \%$ & 1.86 \\
\hline A03 & 0 & $0 \%$ & 0 & $0 \%$ & 10 & $12 \%$ & 62 & $73 \%$ & 13 & $15 \%$ & 1.97 \\
\hline A04 & 0 & $0 \%$ & 9 & $11 \%$ & 40 & $46 \%$ & 26 & $31 \%$ & 10 & $12 \%$ & 2.56 \\
\hline A05 & 0 & $0 \%$ & 14 & $16 \%$ & 43 & $51 \%$ & 28 & $33 \%$ & 0 & $0 \%$ & 2.83 \\
\hline B01 & 0 & $0 \%$ & 11 & $13 \%$ & 29 & $34 \%$ & 37 & $44 \%$ & 8 & $9 \%$ & 2.51 \\
\hline B02 & 0 & $0 \%$ & 0 & $0 \%$ & 5 & $6 \%$ & 41 & $48 \%$ & 39 & $46 \%$ & 1.60 \\
\hline B03 & 0 & $0 \%$ & 0 & $0 \%$ & 9 & $11 \%$ & 55 & $64 \%$ & 21 & $25 \%$ & 1.86 \\
\hline B04 & 0 & $0 \%$ & 17 & $20 \%$ & 41 & $48 \%$ & 27 & $32 \%$ & 0 & $0 \%$ & 2.88 \\
\hline B05 & 0 & $0 \%$ & 9 & $11 \%$ & 41 & $48 \%$ & 35 & $41 \%$ & 0 & $0 \%$ & 2.70 \\
\hline
\end{tabular}

TABLE II. THE DETERMINED DIMENSIONS OF THE THEORETICAL AND PRACTICAL INSTRUCTION

\begin{tabular}{|c|l|l|}
\hline \multirow{4}{*}{$\begin{array}{c}\text { A } \\
\text { Measurement of } \\
\text { theoretical teaching } \\
\text { content }\end{array}$} & A01 & traditional teaching-oriented content \\
\cline { 2 - 3 } & A02 & object-oriented class distribution \\
\cline { 2 - 3 } & A03 & software testing courses \\
\cline { 2 - 3 } & A04 & evaluation methods of final examination \\
\hline \multirow{2}{*}{$\begin{array}{c}\text { Beasurements } \\
\text { experimental teaching } \\
\text { contents }\end{array}$} & A05 & the lecturer's ways of teaching \\
\cline { 2 - 3 } & B01 & the complete degree of experimental equipment \\
\cline { 2 - 3 } & B02 & class distribution of the experimental teaching \\
\cline { 2 - 3 } & B03 & completion of the project (independently) \\
\cline { 2 - 3 } & B04 & the operability of the project \\
\hline
\end{tabular}

\section{B. References}

Quarter of the graph model has both advantages and disadvantages, its drawback is that errors are not considered so that data is not enough precise. Therefore, the principal component analysis is used in this article in order to determine the degree of concern of the individual indicators.

Principal component analysis was first proposed by Hotelling in 1933. The main idea of this method is dimensionality reduction[22].This article uses the software of SPSS17.0 to solve the process of principal component.

\section{Figures and Tables}

Firstly, all data were taken for validity and reliability tests, KMO value is 0.654 , Bartlett Chi square value is 166.961, degrees of freedom is 45 , and significance level is 0.000 . The above data shows that there is a correlation between different variables; the factor analysis can be carried out. We get the correlation coefficient matrix by SPSS17.0 and the results are shown in table 3. The Eigen value of the correlation matrix, individual contribution and

cumulative contribution rate are shown in table 4. It can be seen from Table 3, the first three characteristic roots of the correlation matrix are 2.597, 1.955 and 1.118. The cumulative contribution rate of the three is 56.691percent. According to the principles that characteristic value is larger than 1 , we got 3 common factors I1, I2 and I3 which are shown in table 5.

TABLE III. CORRELATION MATRIX

\begin{tabular}{|c|l|l|}
\hline \multirow{3}{*}{$\begin{array}{c}\text { A } \\
\text { Measurement of } \\
\text { theoretical teaching } \\
\text { content }\end{array}$} & A01 & traditional teaching-oriented content \\
\cline { 2 - 3 } & A02 & object-oriented class distribution \\
\cline { 2 - 3 } & A03 & software testing courses \\
\cline { 2 - 3 } & A04 & evaluation methods of final examination \\
\cline { 2 - 3 } & A05 & the lecturer's ways of teaching \\
\hline \multirow{3}{*}{$\begin{array}{c}\text { Beasurements } \\
\text { experimental teaching } \\
\text { contents }\end{array}$} & B01 & the complete degree of experimental equipment \\
\cline { 2 - 3 } & B02 & class distribution of the experimental teaching \\
\cline { 2 - 3 } & B03 & completion of the project (independently) \\
\cline { 2 - 3 } & B04 & the operability of the project \\
\cline { 2 - 3 } & B05 & judgment of the experimental course grade \\
\hline
\end{tabular}


TABLE IV. EXPLANATION OF TOTAL VARIANCE

\begin{tabular}{|c|c|c|c|c|c|c|c|c|c|}
\hline \multirow[b]{2}{*}{ Component } & \multicolumn{3}{|c|}{ Initial Eigenvalues } & \multicolumn{3}{|c|}{ Extraction Sums of Squared Loadings } & \multicolumn{3}{|c|}{ Rotation Sums of Squared Loadings } \\
\hline & Total & \% of Variance & Cumulative\% & Total & $\%$ of Variance & Cumulative $\%$ & Total & $\%$ of Variance & Cumulative\% \\
\hline 1 & 2.597 & 25.965 & 25.965 & 2.597 & 25.965 & 25.965 & 2.090 & 20.896 & 20.896 \\
\hline 2 & 1.955 & 19.545 & 45.511 & 1.955 & 19.545 & 45.511 & 1.964 & 19.636 & 40.532 \\
\hline 3 & 1.118 & 11.181 & 56.691 & 1.118 & 11.181 & 56.691 & 1.616 & 16.159 & 56.691 \\
\hline 4 & 0.972 & 9.721 & 66.413 & & & & & & \\
\hline 5 & 0.919 & 9.189 & 75.602 & & & & & & \\
\hline 6 & 0.646 & 6.463 & 82.748 & & & & & & \\
\hline 7 & 0.568 & 5.683 & 87.748 & & & & & & \\
\hline 8 & 0.476 & 4.764 & 92.513 & & & & & & \\
\hline 9 & 0.404 & 4.045 & 96.557 & & & & & & \\
\hline 10 & 0.344 & 3.433 & 100.000 & & & & & & \\
\hline
\end{tabular}

TABLE V. COMPONENT MATRIX

\begin{tabular}{|c|c|c|c|}
\hline \multirow{2}{*}{} & \multicolumn{3}{|c|}{ Component } \\
\cline { 2 - 4 } & 1 & 2 & 3 \\
\hline A01 & 0.645 & -0.527 & 0.053 \\
A02 & 0.291 & -0.600 & 0.114 \\
A03 & 0.638 & -0.300 & 0.383 \\
A04 & 0.171 & 0.708 & -0.003 \\
A05 & 0.371 & 0.510 & 0.459 \\
B01 & 0.682 & 0.020 & -0.403 \\
B02 & 0.321 & 0.070 & 0.609 \\
B03 & 0.629 & -0.117 & -0.317 \\
B04 & 0.666 & 0.367 & -0.330 \\
B05 & 0.340 & 0.558 & 0.051
\end{tabular}

Extraction Method: Principal Component Analysis. a. 3 components extracted.

\section{Other Recommendations}

The concern score of each degree is calculated as follows:

With the data in table 3 divided by principal component corresponding characteristic value of the secondary square roots, and then we get the three main component of each index corresponding coefficient that are as follows:

$\mathrm{I} 1=0.4002 \mathrm{X} 1+0.1806 \mathrm{X} 2+0.3595 \mathrm{X} 3+0.1061 \mathrm{X} 4+0.230$ $2 \times 5+0.4232 \times 6+0.1992 \times 7+0.3903 \times 8+0.4133 \times 9+0.2110$ $\mathrm{X} 10$

$\mathrm{I} 2=-0.3769 \mathrm{X} 1-0.4291 \mathrm{X} 2-0.2146 \mathrm{X} 3+0.5064 \mathrm{X} 4+0.364$ $8 \times 5+0.0143 \times 6+0.05006 \times 7-0.0837 \times 8+0.2625 \times 9+0.399$ $1 \mathrm{X} 10$

$\mathrm{I} 3=0.0501 \mathrm{X} 1+0.1078 \mathrm{X} 2+0.3622 \mathrm{X} 3-0.0028 \mathrm{X} 4+0.434$ $1 \times 5-0.3811 \times 6+0.5760 \times 7-0.2998 \times 8-0.3121 X 9+0.0482 \mathrm{X}$ 10

The sum that is generated through the coefficients which are in correspondence with each indicator are multiplied by their corresponding contribution rates in I1 (the first principal constituent), and divided by the contribution rate of the third principal constituent, then added by the sum of the coefficients which are in correspondence with each indicator multiplied by their corresponding contribution rates in I2 (the second principal constituent) and divided by the contribution rate of the third principal constituent, finally added by the sum of the coefficients which are in correspondence with each indicator multiplied by their corresponding contribution rates in $\mathrm{I} 3$ (the third principal constituent) and divided by the contribution rate of the third principal constituent, thus the composite score model are generated as follows:

$\mathrm{Y}=0.063 \mathrm{X}_{1}-0.044 \mathrm{X}_{2}+0.179 \mathrm{X}_{3}+0.223 \mathrm{X}_{4}+0.317 \mathrm{X}_{5}+0.1$ $24 \mathrm{X}_{6}+0.222 \mathrm{X}_{7}+0.091 \mathrm{X}_{8}+0.218 \mathrm{X}_{9}+0.244 \mathrm{X}_{10}$

The corresponding coefficient of composite score for each indicator in the model is equal to the weights of each indicator which are shown in the table 6.

TABLE VI. COMPONENT MATRIX

\begin{tabular}{|c|c|c|c|c|c|}
\hline Index & $\mathrm{A} 01$ & $\mathrm{~A} 02$ & $\mathrm{~A} 03$ & $\mathrm{~A} 04$ & $\mathrm{~A} 05$ \\
\hline Attention & 0.063 & -0.044 & 0.179 & 0.223 & 0.317 \\
\hline Index & $\mathrm{B} 01$ & $\mathrm{~B} 02$ & $\mathrm{~B} 03$ & $\mathrm{~B} 04$ & $\mathrm{~B} 05$ \\
\hline Attention & 0.124 & 0.222 & 0.091 & 0.218 & 0.244 \\
\hline
\end{tabular}

\section{DISCUSSION}

A quarter of graph model is constructed according to the data in table 2 and table 6 . Various indicators concern is as the horizontal axis and various scores of index satisfaction as the longitudinal axis. The results are shown in Fig. 4 


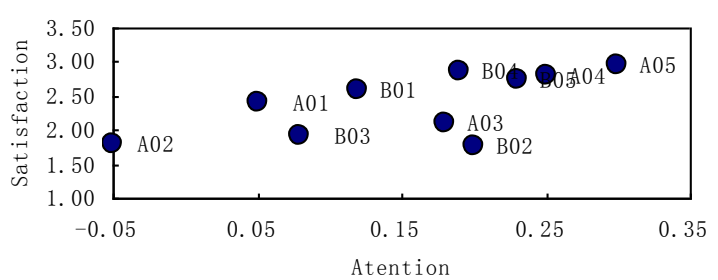

Ps:A01,traditional teaching-oriented content;A02, object-oriented class distribution; A03, software testing courses;A04, evaluation methods of final examination; $\mathrm{A} 05$, the lecturer's ways of teaching (purely theoretical teaching);B01, the complete degree of experimental equipment.B02: class distribution of the experimental teaching;B03, completion of the project (independently);B04, the operability of the project;B05, judgment of the experimental course grade.

Figure 4. comparison quadrants of SE

By the satisfaction of the teaching contents of "software engineering", the strengths and weakness of this course can be visually got from the figure 3 which will point out a direction for the development of instruction reform.

The first quadrant is characterized by high satisfaction and awareness, called the district of advantage .There are 4 indicators in this region. What we need to do is to maintain this phenomenon.

The second quadrant is the maintain area that is characterized by the low attention of students and a high degree of satisfaction. Indicators in this area are traditional teaching-oriented content and the complete degree of experimental equipments. In a word, the students were impressed by the traditional instruction contents and experimental teaching.

The third quadrant is the opportunity area which is characterized by very low degree of concern and satisfaction so that we should pay more attention on this district. Indicators in this area are object-oriented contents in theoretical instruction and the completion of the project in experimental teaching. In the theory of teaching, object-oriented teaching content is more easy to be accepted compared with traditional teaching-oriented content, and more suitable for the future of software development; in experimental teaching, the way that completing the project as a team are more likely to be accepted.

The fourth quadrant is the improvement area which is characterized by low satisfaction but high attention. The indicators in this area should be paid more attention and taken measures timely. The data results show that we should modify contents of software testing and appropriately increase the content of this part. Experimental instruction should be paid close attention too.

\section{CONCLUSION}

Overall, analysis of the results is consistent with objective reality. The method that using a quarter of graph structure for the satisfaction of students is an effective way for diagnosing the problems existed in the curriculum. In this paper, only 10 indicators as a software engineering curriculum reform system are selected and the number of objects is limited, so the results have their limitations. At the same time, the foundation for the development of instruction reform was laid in this research. In the future, we can take measures for the comparative study in different colleges and increase the number of samples so that we can obtain more valuable conclusions for future development of the software engineering curriculum.

\section{REFERENCES}

[1] Zhu Sanyuan, Qian Xueqiu, Su Weimin. Introduction to software engineering technology [M]. Beijing Science, Press, 2002

[2] Zheng Renjie, Yin Renkun, Tao Yonglei. Practical software engineering [M]. Beijing: Tsinghua University press, 1996

[3] Nancy R. Mead. Software engineering education: How far we've come and how far we have to go. Journal of Systems and Software, 2009

[4] Bill Williams. Tracking Engineering Education Research and Development.2012

[5] Yangzhiyun,Liujianbin. Software engineering task driven teaching mode exploration and construction [J] Higher Education of Science. 2005,6:59-62

[6] Service Science, Management and Engineering Education: A Unified Model for University. Wei Jianliang, Chen Jianhua, Zhu Qinghua IJSSMET 2010

[7] XuJing .My views on teaching reform of software engineering. CaiZhi. 2009.12

[8] Zhang Haifan, Introduction to software engineering [M], Beijing: Tsinghua University, 2005

[9] Mark, Bourque, Pierre, etc. IEEE Software 2011-4 ProQuest journal

[10] Yang Cai, Jia Songhao, Zhang Hai . Thinking of the teaching reform and practice of software engineering. Yu Jiao Shu Yu Ren. 2010.2

[11] Li hongmei, Zhang hongyan, luwei. Competence-oriented software engineering practice teaching system $[\mathrm{J}]$. Research in Higher Education of Engineering. 2009,02:84-87

[12] Chung-Yang Chen,Kao-Chiuan Teng .The design and development of a computerized tool support for conducting senior projects in software engineering education.Computers \& Education 2011DBLP Document

[13] Alok Mishra,Nergiz Ercil Cagiltay,Ozkan Kilic. Software engineering education: some important dimensions.European Journal of Engineering Education 2007-3 Taylor \& Francis journal

[14] Study on foreign teaching software engineering method $\mathrm{Li}$ Guangyuan . computer education. 2011.1

[15] Application of the method of software engineering in the university teaching management system. Wang Hui Computer technology and development 2007.5

[16] The implementation of software engineering ideas in computer language teaching implement Wanf Canhui,Lin LangdieHigher Education Forum 2010.1

[17] $\mathrm{Wu}$ Guodong,Tu Lijing. Exploration and practice of the teaching mode of the integration of software engineering .computer education .2010 .8

[18] Guo Jun, Zhang Hongxia, Wang Yunsheng, Zhang Bin.The core concept of modern software engineering teaching system and practice based on the multiple perspectives. Experimental technology and management. 2010.8 
[19] Hekekang, Constructivism - the theoretical basis of the innovation of traditional teaching. E-EDUCATION RESEARCH. 1997(03):3-9.

[20] Jincaiqin,Wangwanzi. Comparison of several software engineering professional training programmes in universities in China [J] China Education Innovation Herald. 2011,11:149-150

[21] Tianjinlan, software engineering series course analysis of foreign University [J] IT Education,2004,5:45-47.

[22] Hexiaoqun. Modern statistical analysis methods and application [M].Beijing. China renmin university press. 2007,8. 